\title{
Mechanical Joining of the Combination of Steel Sheets and Aluminium Alloy Sheets
}

\author{
Luboš Kašcák ${ }^{1 *}$, Emil Spišák ${ }^{2}$ \\ ${ }^{1}$ Technical University of Košice, Faculty of Mechanical Engineering, Department of Computer Support of Technology, Mäsiarska 74, 04001 Košice, \\ Slovakia \\ ${ }^{2}$ Technical University of Košice, Faculty of Mechanical Engineering, Department of Mechanical Engineering Technology and Materials, Mäsiarska 74, \\ 04001 Košice, Slovakia
}

\begin{abstract}
Constructions of steel sheets and sheets from aluminium alloys are widely used in car body production to reduce the total car weight. The reduction in car weight is needed to improve fuel efficiency. Aluminium alloys play a more important role in future car body generations. Properties of this material give some advantages and open the way for new applications in the automotive industry. It is not possible to join the multiply material combination by conventional joining methods such as resistance spot welding. Therefore, alternative joining methods are being developed. One of the alternatives is mechanical joining - clinching. Clinching is suitable for joining the thin sheets from ferrous and non-ferrous metals. Mechanical clinching is also well known as a speed and efficient cold joining process, mainly for joining the thin-sheet applications. In this process, the local plastic deformation of the sheets is created by the clinching tool. The paper focuses on the evaluation of the properties of mechanically clinched joints, realized on the combination of the zinc-coated steel sheets DC06 and H22OPD and sheets from aluminium alloys EN AW 5754 with various hardness H11, H22 and H24 and EN AW 6082. The tensile test and a metallographic observation were used to evaluate the clinched joint properties. Mechanical clinching proved to be suitable technique for joining the observed combination of steel sheets and aluminium alloy sheets. It is necessary to consider the orientation of the sheets relative to punch and die.
\end{abstract}

Keywords: Mechanical joining; steels sheets; aluminium sheets; tensile test; metallography.

\section{Introduction}

Modern lightweight car bodies are becoming more and more complex than previous constructions. The materials nowadays are used for a more specific field of application and more high strength steels are used as well as other materials like aluminium alloys, stainless steels, reinforced polymers. The joining of these materials often requires new or modified joining processes [1-3]. Lightweight materials like aluminium alloys and high-strength steels are used in modern automotive production as well as conventional steel sheets of drawing quality for multi-material body design. These materials are not welded by the resistance spot welding process commonly used to join steel sheet for the automotive body because of the different melting points and thermal conductivity. Hence, an alternative method is required to achieve the successful multi-material body [4-5]. The mechanical joining technologies have been proved effective for joining lightweight materials with high strength, mainly clinching, clinch-riveting and self-piercing riveting. Among these mechanical joining methods, the clinching 
technology has been developed rapidly. Compared with clinching technology, clinch-riveting and self-piercing riveting require a rivet, which may increase the weight of the joint. However, the higher forming load is necessary $[2,6]$.

Mechanically clinched joints are used in automotive assemblies [7], building components [8], even in electrical industries. Mechanical clinching is a cold joining process of sheets by local hemming with a punch and die. The material between punch and die is forced into a radial flow to form the undercut. This method belongs to a group of plastic joining technology. The joined sheets are deformed locally by creating a mechanical interlock. It is used for joining thin sheets in range of $0.5 \mathrm{~mm}$ to $4 \mathrm{~mm}$ single sheet thickness, up to a total joint thickness of about $20 \mathrm{~mm}$ [9]. The load-bearing capacity of the clinched joint mainly depends on the geometrical parameters of the joint profile which is mainly influenced by process parameters and clinching die [10].

Joinability of aluminium alloys with reduced ductility using modified tool set geometry and sheet preheating was performed in $[10,11]$. Combination of steel sheet and aluminium alloy sheet was studied in [12], where influence of pre-strain of materials on the joint quality was observed.

Joining of steel sheets and aluminium alloys has been investigated intensively. Achieving sufficient quality of the joints is the challenge because of significant differences between steels and aluminium alloys: mechanical properties, melting temperature, thermal expansion coefficient, and others [13]. Plastic deformation of the sheets forms the clinched joint in the mechanical clinching process, so the melting point and other chemical properties have little effect on the joining of different materials [14].

The research is focused on the evaluation of properties of the clinched joints made with the combination of galvanized high-strength steel sheets H220PD, steel sheets of drawing quality DC06 and aluminium alloy sheets EN AW 5754 and EN AW 6082.

\section{Experimental Materials and Methods}

The mechanical clinching process is an effective joining method based on the plastic deformation of the sheet materials. The joined materials are deformed locally to made a clinched joint. The principle of clinching process was described in [15]. A punch forms two or more materials to be joined into a specially formed die. A button shape is formed on the underside and provides an interlock between the sheets - Figure 1. A large interlock can prevent the button separation failure, and a thick neck can prevent the neck fracture failure.

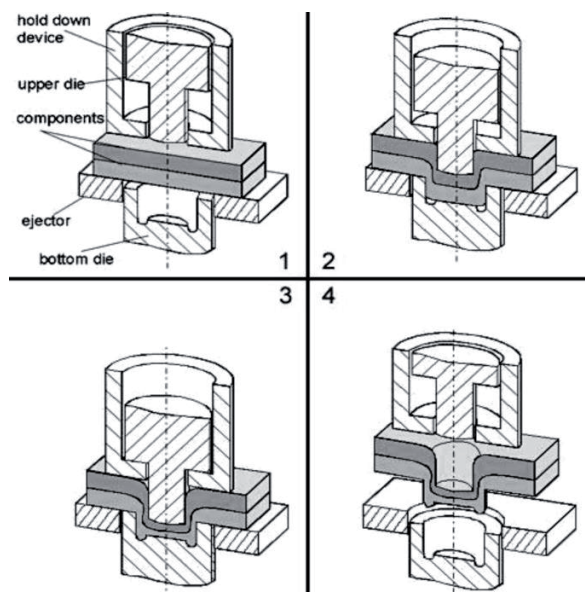

Fig. 1: Principle of mechanical clinching process [1].

The process of single-step clinching, as illustrated in Fig.1, can be described as:

Step 1: The punch and blank holder move downward, the work pieces are clamped and fixed by spring force of the blank holder.

Step 2: The material flows into the bottom die cavity forming a cup. The process parameters and dimensions of the punch and die are finely tuned to the sheet thickness of the work pieces. This insures that no material is laterally drawn into the joint from surrounding area.

Step 3: Finally, the thickness of the cup's bottom is reduced by upsetting and the material forced into the die groove and in lateral direction, forming the necessary undercut.

Step 4: After reaching a maximum force or a displacement, the punch is retracted and the clamping force relieved. The joint connection requires no finishing.

The combination of hot-dip galvanized HSLA steel sheet H220PD with the thickness of $0.8 \mathrm{~mm}$ as well as hot-dip galvanized steel sheet DC06 of drawing quality with the thickness of $0.8 \mathrm{~mm}$, both combined 
with aluminium alloy EN AW $5754(\mathrm{H} 11, \mathrm{H} 22$ and $\mathrm{H} 24$ ) with the thickness of $0.8 \mathrm{~mm}$ and EN AW 6082 with the thickness of $0.9 \mathrm{~mm}$ were observed. The basic mechanical properties of materials used for mechanical clinching (Rp0.2 - yield strength, $\mathrm{Rm}$ - ultimate tensile strength, A80 - elongation) are shown in Table 1. The chemical composition of these materials are shown in Table 2. The diameters of the clinching tool was $\varnothing 5 \mathrm{~mm}$ of the die and $\varnothing 3.6 \mathrm{~mm}$ of the punch.

Table 2: Chemical composition of used sheets (in [\%] of wt).
Table 1: Basic mechanical properties of joined sheets.

\begin{tabular}{|l|l|l|l|}
\hline Material & $\begin{array}{l}\text { Rpo.2 } \\
{[\text { MPa] }}\end{array}$ & $\begin{array}{l}\text { Rm } \\
{[\text { MPa] }}\end{array}$ & $\begin{array}{l}\text { Aso } \\
{[\%]}\end{array}$ \\
\hline H220PD & 238 & 382 & 36 \\
\hline DC06 & 170 & 305 & 41 \\
\hline EN AW 5754 H11 & 137 & 221 & 25 \\
\hline EN AW 5754 H22 & 160 & 246 & 20 \\
\hline EN AW 5754 H24 & 138 & 141 & 6 \\
\hline EN AW 6082 & 313 & 341 & 12 \\
\hline
\end{tabular}

\begin{tabular}{|l|l|l|l|l|l|l|l|}
\hline Material & $\mathbf{C}$ & $\mathbf{M n}$ & $\mathbf{S i}$ & $\boldsymbol{P}$ & $\mathbf{N i}$ & $\mathrm{Al}$ & $\mathbf{C u}$ \\
\hline H220PD & 0.012 & 0.435 & 0.119 & 0.057 & 0.013 & 0.041 & 0.040 \\
\hline DC06 & 0.020 & 0.071 & 0.010 & 0.017 & 0.011 & 0.055 & 0.038 \\
\hline EN AW 5754 & - & 0.5 & 0.4 & - & - & Balance & 0.1 \\
\hline EN AW 6082 & - & 0.8 & 0.9 & - & - & Balance & 0.1 \\
\hline Material & $\mathrm{Cr}$ & $\mathrm{Ti}$ & $\mathrm{V}$ & $\mathrm{Zn}$ & $\mathrm{Mg}$ & Co & Fe \\
\hline H220PD & 0.046 & 0.033 & 0.012 & - & - & 0.047 & Balance \\
\hline DC06 & 0.022 & 0.062 & 0.008 & & & 0.035 & Balance \\
\hline EN AW 5754 & 0.3 & 0.4 & - & 0.2 & $2.6-3.6$ & - & 0.4 \\
\hline EN AW 6082 & 0.25 & 0.1 & - & 0.2 & 1.0 & - & 0.5 \\
\hline
\end{tabular}

Tension test and metallographic observation were performed to evaluate the properties of the clinched joints.

The following material combination of steel sheets and aluminium sheets were chosen for clinching (P-punch side of specimen, D-die side of specimen):

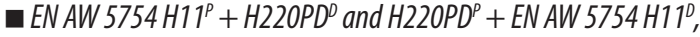
- EN AW $5754 \mathrm{H1}^{\mathrm{P}}+\mathrm{DC} \mathrm{C}^{\mathrm{D}}$ and DCO6 $6^{\mathrm{P}}+$ EN AW $5754 \mathrm{H1} 1^{\mathrm{D}}$,
- EN AW $5754 \mathrm{H} 22^{p}+H 220 P D^{D}$ and H22OPD + EN AW $5754 \mathrm{H}^{2} 2^{\circ}$,
- EN AW 5754 H22 + DCO6D and DCO6P + EN AW 5754 H22D,
- EN AW $5754 \mathrm{H} 24^{\rho}+H 220 P D^{\circ}$ and $H 220 P D^{p}+$ EN AW 5754 H24

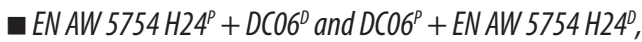
- EN AW 6082 + H22OPD and H22OPD + EN AW 6082
- EN AW $6082^{\circ}+D C 06^{\circ}$ and DC06 + EN AW $6082^{\circ}$.

The sample dimensions were given by STN 05 1122 standard (Figure 2a). Since the possibility of joining steel sheets and aluminium alloy sheets was evaluated, the influence of position of the joined sheets relative to the punch and die on the load bearing capacity of the clinched joints was observed as well. Ten samples were prepared for every combination of sheets. The surfaces of the specimens were not cleaned before mechanical clinching. The parameters determining the clinching joint such as neck thickness $\left(t_{n}\right)$, undercut $\left(t_{s}\right)$ and bottom thickness $(x)$ are shown in Figure $2 b$.

(a)

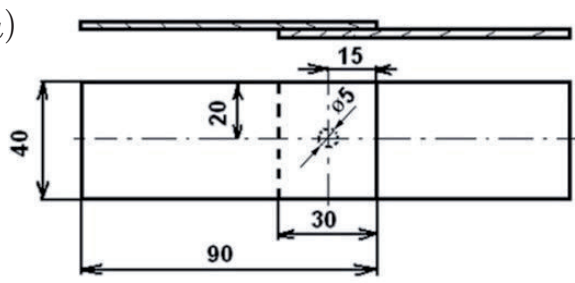

(b)

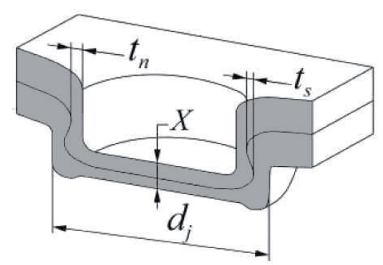

Fig. 2: (a) Sample for tensile test. (b) Parameters of clinching joint.

The load-bearing capacity of the clinched joints were measured from static tensile test according to standard STN 05 1122. The tensile test was used for measuring the maximum force Fmax until failure of the joints occurred. The test was carried out on the 
metal strength testing machine TIRAtest 2300 with the loading speed of $8 \mathrm{~mm} / \mathrm{min}$. Further tests for the quality evaluation of clinched joints included the metallographic observation.

\section{Results and Discussion}

The tensile test was performed to characterize the static behaviour of the clinched joints of observed combination of ferrous and non-ferrous metals. The load-displacement curves with maximum values of load bearing capacity obtained from tensile test are shown in in Figure 3 and 4. The forms of curve indicate the behaviour of the clinched joints under load force $F$.
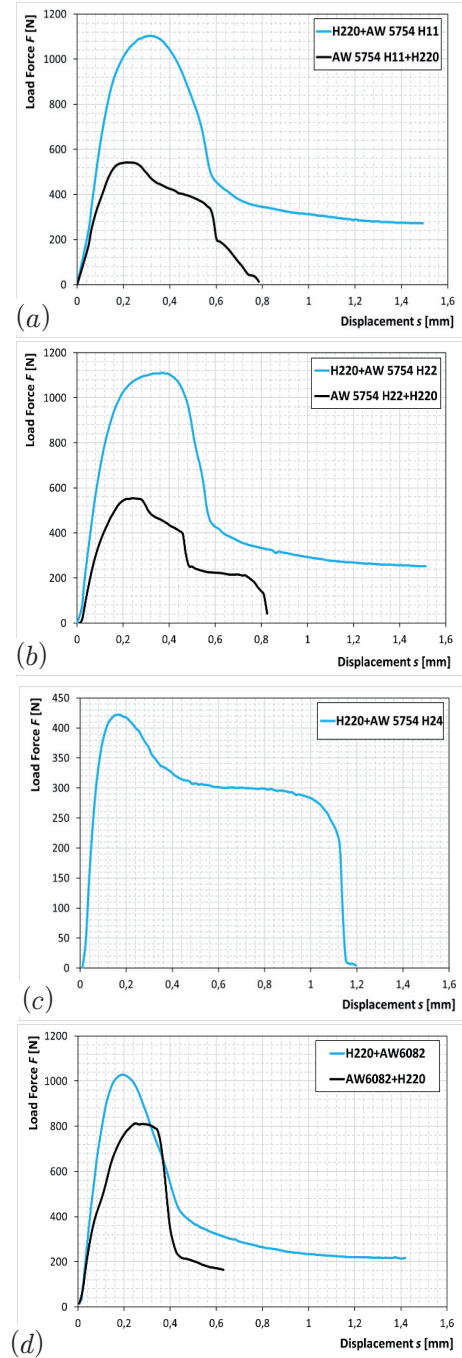

Fig. 3: Load-displacement curves of clinched joints of combination: (a) H22OPD and AW 5754 H11, (b) H22OPD and AW 5754 H22 (c) H22OPD and AW 5754 H24, (d) H22OPD and AW 6082.
When aluminium alloy was positioned on the punch side of the clinching tool, then the lowest values of load-bearing capacity Fmax were measured on the samples, except for the samples with the combination of EN AW $5754 \mathrm{H} 24$ and H22OPD, where aluminium alloy sheet was positioned on the punch side of the tool. The load-bearing capacity of these samples were not measured (Figure 3c), since the clinched joints were not successfully formed. The clinch joint failed during the clinching process.

All observed successfully formed samples with steel sheet H220PD oriented on the punch side of tool showed the higher values of load-bearing capacity.
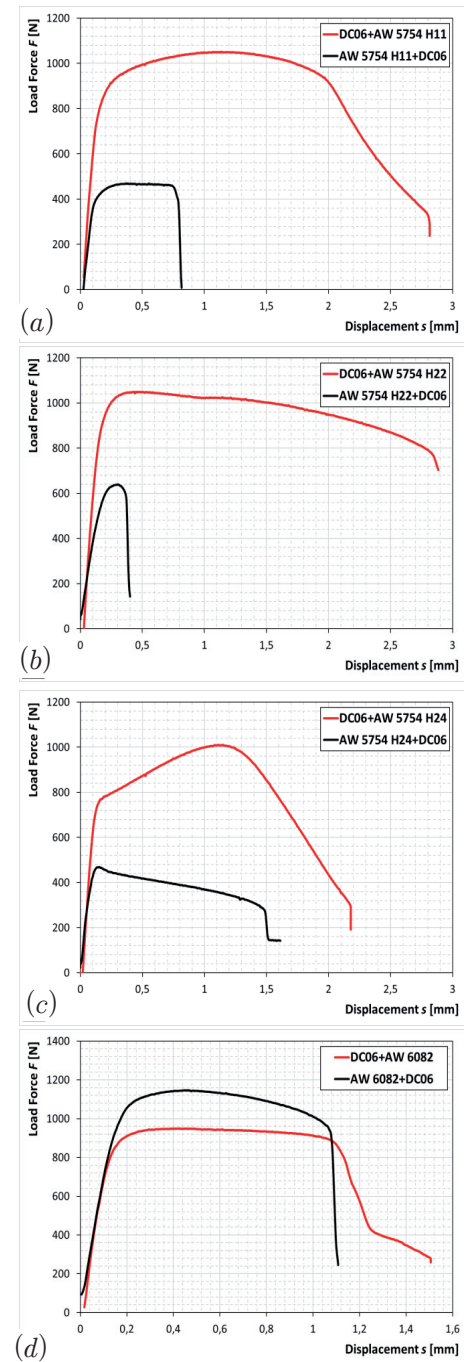

Fig. 4: Load-displacement curves of clinched joints of combination: (a) DCO6 and AW 5754 H11, (b) DCO6 and AW 5754 H22, (c) DCO6 and AW 5754 H24, (d) DCO6 and AW 6082. 
Table 3: The characteristic parameters of clinched joints in [ $\mathrm{mm}]$ (NM-not measured).

\begin{tabular}{|c|c|c|c|c|c|c|c|}
\hline \multicolumn{2}{|c|}{ Material combination } & \multirow{2}{*}{$\begin{array}{l}\left.\text { Neck thickness (t } t_{n}\right) \\
0.187\end{array}$} & \multirow{2}{*}{\begin{tabular}{|l|} 
Undercut $\left(t_{s}\right)$ \\
0.156
\end{tabular}} & \multicolumn{2}{|c|}{ Material combination } & \multirow{2}{*}{\begin{tabular}{|l|} 
Neck thickness $\left(t_{n}\right)$ \\
0.396 \\
\end{tabular}} & \multirow{2}{*}{\begin{tabular}{|l|} 
Undercut $\left(t_{s}\right)$ \\
0.047 \\
\end{tabular}} \\
\hline$H 220 P D$ & $H 11$ & & & $D C 06$ & $H 11$ & & \\
\hline$H 11$ & H22OPD & 0.178 & 0.061 & $H 11$ & $D C 06$ & 0.315 & 0.019 \\
\hline$H 220 P D$ & $H 22$ & 0.188 & 0.210 & $D C 06$ & $H 22$ & 0.318 & 0.092 \\
\hline H22 & H22OPD & 0.183 & 0.083 & $\mathrm{H} 22$ & $D C 06$ & 0.285 & 0.054 \\
\hline$H 220 P D$ & $H 24$ & 0.180 & 0.145 & $D C 06$ & $H 24$ & 0.387 & 0.037 \\
\hline$H 24$ & H22OPD & 0.172 & 0.055 & $H 24$ & $D C 06$ & 0.362 & 0.024 \\
\hline$H 220 P D$ & AW 6082 & 0.145 & 0.105 & $D C 06$ & AW 6082 & 0.303 & 0.73 \\
\hline AW 6082 & H22OPD & NM & NM & AW 6082 & $D C 06$ & 0.320 & 0.037 \\
\hline
\end{tabular}

Figure 4 shows the load-displacement curves of steel sheet DC06 and aluminium alloys sheets. All observed samples with steel sheet DC06 oriented on the punch side of tool showed the higher values of load-bearing capacity, with the exception of samples of combination DC06 and EN AW 6082, as shown in Figure 4d.

Metallographic observation confirmed the suitability of mechanical clinching as a joining method for material combinations of H220PD steel as well as DC06 steel with the observed aluminium alloys. No cracks or failures occurred during the joining process, except above mentioned combination of AW 5754 H24 and H22OPD. The differences among samples were observed mainly in the interlocking area - in neck thickness $\left(t_{n}\right)$ and undercut $\left(t_{s}\right)$ area. The measured values of neck thicknesses and undercuts are shown in Table 3.

In combination of H220PD steel sheet and all observed EN AW 5754 aluminium alloy sheets, the higher values of neck thickness $\left(t_{n}\right)$ and undercut $\left(t_{s}\right)$ was measured on the samples with H220PD steel sheet positioned under punch of the clinching tool. This fact, together with higher mechanical properties of H220PD steel sheet, led to the higher values of load-bearing capacity measured from tensile test. The interlocking areas of the material combination of H22OPD and EN AW5754 H22 are shown in Figure 5.

When combination of DC06 steel sheet and all observed EN AW 5754 sheets were prepared, the higher values of neck thickness (tn) and undercut (ts) was measured on the samples with DC06 steel sheet positioned under punch of the clinching tool as well. The higher mechanical properties of DC06 steel sheet in comparison to EN AW 5754 alloy sheets and the measured parameters of clinched joints led to the higher values of load-bearing capacity. The interlocking areas of the material combination of DC06 and EN AW5754 H22 are shown in Figure 6.

Figure 7 shows the material combination of DC06 and EN AW 6082 sheets. In this material combination, the higher values of neck thickness (tn) were measured on the samples with EN AW 6082 aluminium alloy sheets positioned on the punch side. This aluminium alloy has higher values of Rp0.2 and Rm in comparison to DC06 steel sheet (Table 1). These factors led to higher values of loadbearing capacity measured from the tensile test, although the value of undercut (ts) in EN AW 6082 sheet was significantly lower.

\section{Conclusions}

The lightweight design of car body is one of the primary methods to realize energy conservation and emission reduction, thus the utilization of light material and structure has become the preferential approach as well as using various combinations of materials, such as combination of conventional deep-drawn steel sheets, high-strength steel sheets and aluminium alloys. Increasing amount of aluminium alloys in car body production lead not only to the question, how to create a part from aluminium alloys, but also how to join such parts, especially when combination of steel and aluminium alloy is required. The mechanical clinching as a method involving localized cold deformation of sheets without using additional elements is appropriate technique for joining the tested combination of materials. The present investigation was aimed at analysing the possibility of joining the combination of hot-dip galvanized steel sheets DC06 and H220PD and aluminium alloys EN AW 5754 and EN AW 6082. The following 

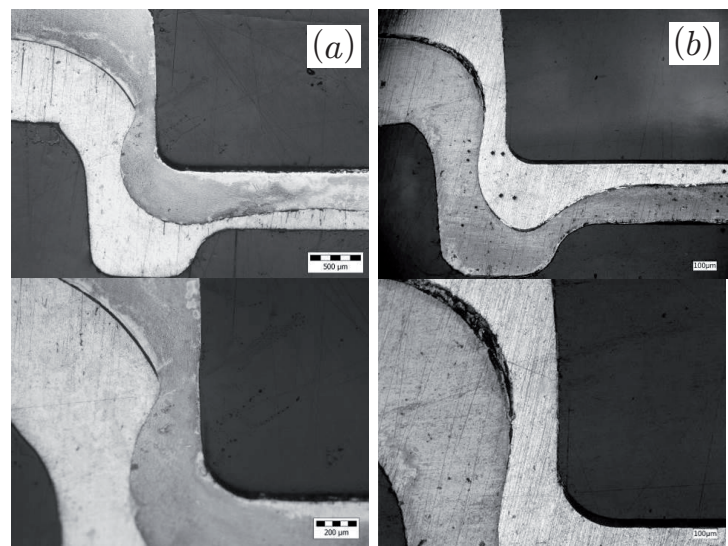

Fig. 5: Interlocking areas of the clinched joints: (a) $H_{22} 20 P D^{P}+A W$ 5754 H22 $2^{D}$ (b) AW 5754 H22 + H22OPD ${ }^{D}$ (P-punch side of specimen, $D$-die side of specimen).

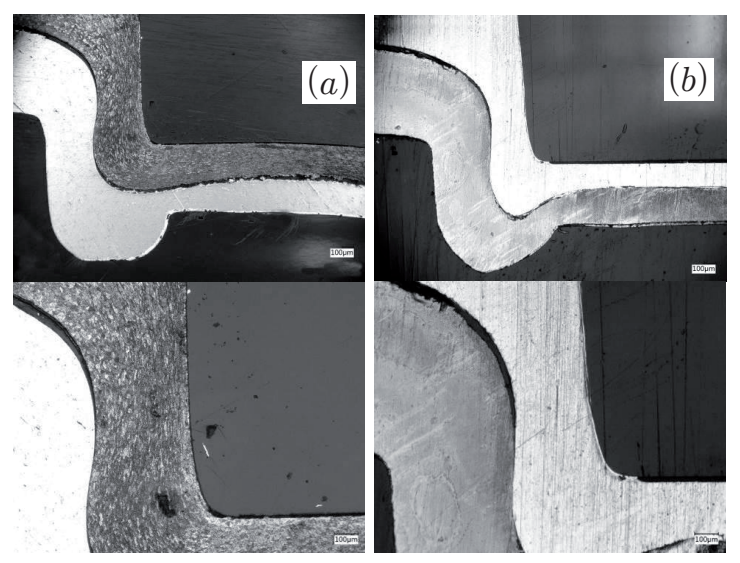

Fig. 6: Interlocking areas of the clinched joints: (a) DCO6 $+A W 5754$ H22 ; (b) AW 5754 H22 + DCO6 ${ }^{D}$ (P-punch side of specimen, D-die side of specimen).
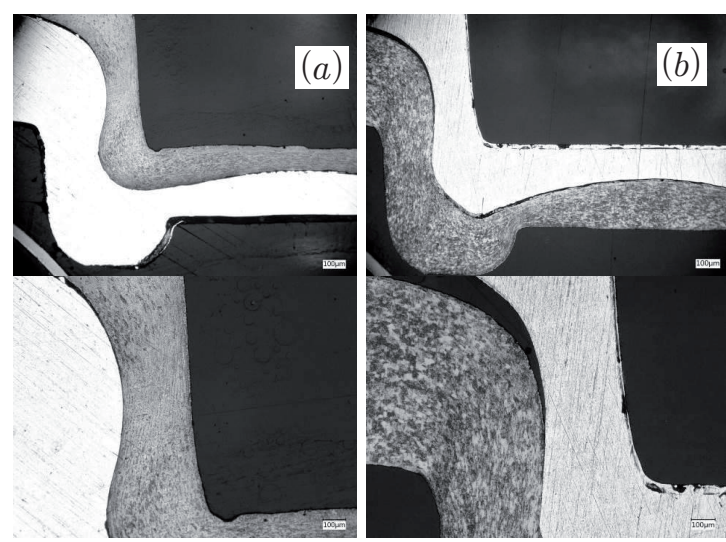

Fig. 7: Interlocking areas of the clinched joints: (a) $D C 06^{P}+A W$ 6082 ${ }^{D}$; (b) AW 6082P $+D C 06^{D}$ (P-punch side of specimen, D-die side of specimen). results were obtained:

- Mechanical clinching is a convenient method for joining the observed combinations of steel sheets and aluminium alloy sheets.

- The high-quality clinched joints were formed as confirmed the tensile test and metallographic observation. The characteristic mechanical interlock was created and no inner defects were observed in the clinched joints of these steel sheets.

- The load bearing capacities of the samples were sufficient and the metallographical analysis confirmed no occurrence of cracks or failures in the area of joints during joining processes, with the exception of samples of H22OPD and aluminium alloy AW 5754 H24 positioned towards the punch. In this case, the clinched joint was not successfully formed.

- The position of the joined sheets relative to the punch and the die of the joining tool plays an important role in load-bearing capacity in the observed combination of steel sheets and aluminium alloys.

- In combinations of materials, where the steel sheet H22OPD or DCO6 was located on the punch side, almost double values of the loadbearing capacity were measured, except samples with DCO6 and EN AW 6082 .

\section{Acknowledgments}

This work was supported by the Slovak Research and Development Agency under the Contract No. APVV-14-0834 and project VEGA No. 1/0441/17.

\section{References and Notes}

[1] Kaščák L., Mucha J., Slota J., Spišák E. (2013). Application of modern joining methods in car production. Ofycina wydawnicza Politechniki Rzeszowskiej, Rzeszów.

[2] Chen Ch., Zhao S., Cui M., Han X., Fan S., Ishida T. (2016). An experimental study on the compressing process for joining Al6061 sheets. Thin-Walled Structures, Vol. 108, pp. 56-63.

[3] Pinger T., Rückriem E.M. (2016). Investigation on the corrosion and mechanical behavior of thin film batch galvanized thick plate components in clinch joints. The International Journal of Advanced Manufacturing Technology, Vol. 86, pp. 29-36.

[4] Lee C.J., Kim J.Y., Lee S.K., Ko D.C., Kim B.M. (2010). Design of mechanical clinching tools for joining of aluminium alloy sheets. Materials \& Design, Vol. 31, pp. 1854-1861.

[5] Mucha J., Kaščák L., Spišák E. (2013). The experimental analysis of forming and strength of clinch riveting sheet metal joint made of different materials. Advances in Mechanical Engineering, Vol. 5, pp. 1-11.

[6] Jiang T., Liu Z.X., Wang P.C. (2015). Quality inspection of clinched joint of steel and aluminum. The International Journal of Advanced Manufacturing Technology, Vol. 76, pp. 1393-1402.

[7] Barnes T.A., Pashby I.R. (2000). Joining techniques for alu- 
minium spaceframes used in automobiles: part II adhesive bonding and mechanical fasteners. Journal of Materials Processing Technology, Vol. 99, pp. 72-79.

[8] Pedreschi R.F., Sinha B.P. (2008). An experimental study of cold formed steel trusses using mechanical clinching. Construction and Building Materials, Vol. 22, pp. 921-931.

[9] Israel M., Mauermann R., Schellnock J. (2013). Thick sheet clinching - joining up to $20 \mathrm{~mm}$ total thickness. Advanced Shipping and Ocean Engineering, Vol. 2, pp. 1-10.

[10] Lambiase F. (2015). Clinch joining of heat-treatable aluminum AA6082-T6 alloy under warm conditions. Journal of Materials Processing Technology, Vol. 225, pp. 421-432.

[11] Lambiase F., Di llio A., Paoletti A. (2015). Joining aluminium alloys with reduced ductility by mechanical clinching. International Journal of Advanced Manufacturing Technology, Vol. 77, pp. 1295-1304.

[12] Jiang T., Liu Z.X., Wang, P.C. (2015). Effect of aluminum prestraining on strength of clinched galvanized SAE1004 steelto-AA6111-T4 aluminum. Journal of Materials Processing Technology, Vol. 215, pp. 193-204.

[13] Huang Z., Yanagimoto J. (2015). Dissimilar joining of aluminum alloy and stainless steel thin sheets by thermally assisted plastic deformation. Journal of Materials Processing Technology, Vol. 225, pp. 393-404.

[14] Chen Ch., Zhao S., Cui M. (2017). Effects of geometrical parameters on the strength and energy absorption of the height-reduced joint. An experimental study on the compressing process for joining Al6061 sheets. The International Journal of Advanced Manufacturing Technology, Vol. 90, pp. 3533-3541.

[15] Spišák E., Kaščák L'. (2014). Mechanical joining of steel sheets in automotive industry. Acta Mechanica Slovaca, Vol. 18, pp. 6-13. 